\title{
Measurement of milk intake by deuterium dilution
}

\author{
A LUCAS, G EWING, S B ROBERTS, AND W A COWARD \\ University of Cambridge and Medical Research Council Dunn Nutrition Unit, Cambridge
}

SUMmaRY In 14 studies, each lasting seven days, on eight bottle fed infants milk intake was measured by deuterium dilution and by weighing the formula consumed and oral losses. Mean (SD) milk intake was 829 (108) g/day when measured by isotope dilution and 837 (98) g/day when measured by direct weighing, giving a mean difference between methods of $1 \cdot 0(5 \cdot 0) \%$. Thus the stable isotope procedure is a potentially useful method for investigating lactation and nutritional problems.

Measurement of milk intake is fundamental to scientific, epidemiological, and clinical research on infant nutrition. Deuterium oxide $\left({ }^{2} \mathrm{H}_{2} \mathrm{O}\right)$, given orally to mother or infant, has been used by some workers to estimate the intake of breast milk. ${ }^{1-3}$ Unlike alternative methods, such as test weighing ${ }^{4}$ or determination by flow meter, ${ }^{5}$ the stable isotope procedure does not need an observer or apparatus to be present at the time of feeding. This method is supported by sound theoretical arguments, ${ }^{6}$ by the consistency of data obtained in this way compared with data obtained by conventional test weighing, ${ }^{7}$ and by studies in animals. ${ }^{89}$ There is little information, however, on the validation of stable isotope methods in infants. ${ }^{40} \mathrm{We}$ investigated the validity of the 'dose to the baby' deuterium dilution method, giving the isotope to infants living at home and being bottle fed, whose intake could be accurately measured.

\section{Patients and methods}

In 14 studies on eight healthy full term infants being bottle fed at 5 to 11 weeks of age milk intake was measured by deuterium kinetics and the results compared with those obtained by weighing the intake of formula feed and oral losses directly. The methods were conducted simultaneously over seven day periods in the infants' homes. Approval was obtained from the ethical committees of the local hospital and Dunn Nutrition Unit.

Accurate data on formula intake were obtained by issuing preweighed bottles of ready to feed formula and weighing the bottles and residual milk contained in them after seven days. Oral spillages and regurgitations were measured by collecting them on preweighed absorbent tissues. Infants with a history of posseting were not included in the study.
Small quantities of extra fluids given orally were weighed carefully and accounted for.

Details of the isotope method and the calculations used have been reported elsewhere, ${ }^{11}$ but the principal steps were as follows. Two samples of urine or saliva were obtained from each infant before the study to determine natural concentrations of deuterium $\left({ }^{2} \mathrm{H}\right)$ in a body fluid. A weighed dose of sterile isotope solution providing about $0 \cdot 1 \mathrm{~g}$ ${ }^{2} \mathrm{H}_{2} \mathrm{O} / \mathrm{kg}$ body water was then given orally under careful supervision to ensure that the whole dose was taken. Samples of the same body fluid (urine or saliva) were collected at four and five hours and then daily for seven days, a period that covered two to three biological half lives of the isotope.

Water output was calculated from the rate of disappearance of deuterium from the body multiplied by its average dilution space ${ }^{9}$ and adjusting for fractionation of deuterium in water vapour. Using the results of water balance studies on the same infants (unpublished data), we took a figure of $13 \%$ of water intake as being subject to fractionation (that is, evaporative loss).

Total water intake was calculated as water output plus water stored during growth. Water stored during growth was derived from the difference between the measured deuterium space at the start of the study and that estimated at the end. ${ }^{11}$ Oral water intake was derived from total water intake minus insensible water intake through lungs and skin $\left(5.7 \%\right.$ of the total, as estimated previously). ${ }^{11}$

Milk intake was calculated from oral water intake, adjusting for any extra water consumed, the known water content of the formula, water derived from oxidation of milk macronutrients, ${ }^{11}$ and water stored in fat and protein (calculated from body water and weight change and published values for 
the protein and water contents of lean body mass). ${ }^{12}$ Calculations indicate, however, that there is no loss of accuracy in the general equation: milk intake= water intake/0.95.

This isotope method has potential sources of error. The calculation of water output depends on the assumption that the average loss of water subject to fractionation (estimated at 13\%) applies to each infant. Nevertheless, a $100 \%$ error in this figure would result in only a $1 \%$ error in water output. The estimation of water intake from water output is subject to error in the measurement of water deposited during growth, though this can be derived precisely by this technique. A fixed assumption, based on average data, is used to estimate insensible water intake, yet in individual infants variations may occur according to minute volume and ambient humidity.

In six subjects a study comparing the two methods was performed on two separate occasions. For the purposes of analysis these studies were treated as independent: firstly, they were separated in time by six weeks, after major changes in body weight, body water, and milk intake had occurred, and, secondly, statistical analysis showed that within subject variation was closely similar to between subject variation when the methods were compared.

\section{Results}

The mean (SD) weight of formula offered to each infant was 841 (100) g/day, and the weight of

Table Comparison of milk formula intake by direct weighing and by deuterium dilution.

\begin{tabular}{|c|c|c|c|}
\hline \multirow{2}{*}{$\begin{array}{l}\text { Total body water } \\
\text { (\% of body weight) }\end{array}$} & \multicolumn{2}{|c|}{ Milk intake $(g)$} & \multirow{2}{*}{$\begin{array}{l}\text { Difference } \\
(\%)\end{array}$} \\
\hline & Weighed & $\begin{array}{l}\text { By deuterium } \\
\text { dilution }\end{array}$ & \\
\hline 70.9 & 993 & 987 & -0.6 \\
\hline $63 \cdot 1$ & 975 & 1021 & $4 \cdot 7$ \\
\hline $72 \cdot 7$ & 733 & 704 & $-4 \cdot 0$ \\
\hline $67 \cdot 1$ & 840 & 859 & $2 \cdot 3$ \\
\hline $66 \cdot 8$ & 743 & 739 & -0.5 \\
\hline $65 \cdot()$ & 879 & 931 & $5 \cdot 9$ \\
\hline $65 \cdot 2$ & 964 & 868 & -9.9 \\
\hline $69 \cdot 6$ & 841 & 86.3 & $2 \cdot 6$ \\
\hline $69 \cdot 9$ & 686 & 628 & $-8 \cdot 5$ \\
\hline $73 \cdot 3$ & 778 & 820 & $5 \cdot 4$ \\
\hline $70 \cdot 6$ & 777 & 758 & $-2 \cdot 5$ \\
\hline 6()$\cdot 1$ & 828 & 794 & $-4 \cdot 1$ \\
\hline $64 \cdot 5$ & 924 & 870 & $-5 \cdot 8$ \\
\hline $65 \cdot 4$ & 758 & 764 & 0.8 \\
\hline Mean (SD) & 837 (98) & $829(108)$ & $-1 \cdot 0$ \\
\hline
\end{tabular}

measured spills and regurgitations was within the range of 1-12 g/day. The Table shows the resultant mean weight of formula ingested weight together with individual values. These data are compared with those derived by the isotope method. The mean values for milk intake determined by the two methods, 837 (98) g/day by weighing and 829 (108) $\mathrm{g} /$ day by isotope, were not significantly different by the paired $t$ test $(t=0.748)$. The correlation coefficient for the two sets of results was $0.93(p<0.001)$. The mean difference (bias) between the methods (deuterium dilution minus weighed intake) was $-1.0 \%$. The standard deviation of this difference was $5.0 \%$, and thus the limits of agreement of the two methods (as defined by Bland and Altman) ${ }^{13}$ were $-11 \%$ to $+9 \%$ (mean difference $\pm 2 \mathrm{SD}$ of difference). The highest individual difference in this study was $9.9 \%$. The Table shows the results of estimates of total body water determined simultaneously by deuterium dilution.

\section{Discussion}

All methods of measuring milk intake are subject to error, and there is no standard against which a new procedure may be validated. ${ }^{6}$ Test weighing has been used as a standard, but small errors on weighing may accumulate if an infant feeds frequently; water losses by evaporation result in weight loss during the feed, and food regurgitated outside the test weighing period will be included as intake. In this study we attempted to avoid some of these difficulties by weighing the intake of the formula directly. We also carefully accounted for oral spills and regurgitations. Milk intake measured by deuterium dilution gave mean values that differed by only $1 \%$ from those obtained by our reference method.

The results of our study show that $95 \%$ of estimations made by the deuterium method could be expected to fall within the range of $-11 \%$ to $+9 \%$ of the weighed intake. Bland and Altman suggested a method for calculating the precision of the estimated mean difference between methods and the corresponding confidence interval. ${ }^{13}$ Using this approach for our sample size of 14 paired observations, the $95 \%$ confidence interval for placing the mean difference between methods (deuterium method $-1 \%$ compared with weighed intake) would be $-3.9 \%$ to $+2.9 \%$. The value of the deuterium method for work on individual subjects, as opposed to populations, for which the method is clearly valid, depends on the acceptable error for a particular study. We suggest that this method is suitable for most clinical and many laboratory investigations in individual patients, but we empha- 
sise that all methods of measuring food or milk intake are liable to significant errors.

Further confirmation of the validity of our method comes from our previous study comparing water intake by isotope dilution and a conventional balance technique in four premature babies. ${ }^{11}$ In contrast, Butte et al found that milk intake measured by test weighing gave a significantly different result from that determined by isotope, with unacceptable differences between methods of up to $65 \%$ in individual comparisons. ${ }^{4}$ That study may have deterred other investigators from using the isotope method, and the differences between their findings and ours require explanation. Our choice of a reference method other than test weighing probably played a key part in the difference. Moreover, we adjusted the weighed intakes for oral losses of milk, though we were careful not to select babies with a history of posseting; oral losses in our study were never above $2 \%$ of intake. We suggest that a further explanation of the differences between the studies is that we chose periods of seven days for both methods whereas Butte et al test weighed infants for only 48 hours and used the isotope procedure either over those two days or for three or five days, thus extending beyond the test weighing period. Though Butte et al studied breast fed infants and we used formula intake as our reference method, we do not believe that this accounts for all the differences observed. Indeed, the less frequent feeding of many formula fed babies may disturb the linear decline in deuterium enrichment by phasic changes in water turnover; theoretically this should make the isotope method more precise in breast fed infants. More recently Vio et al found good agreement between direct weighing and isotope determination of formula intake, but their study was not conclusive because of a technical problem with the isotope procedure that suggested oral loss of the deuterium dose; total body water values of up to $196 \%$ of body weight were obtained. ${ }^{10}$

Test weighing is likely to remain a valuable method of measurement in nutritional studies. As facilitites for deuterium estimation become more widely available, however, we suggest that use of the deuterium dilution method will increase. The choice between giving the dose to the baby (as studied here) or to the mother will depend on the particular study. Giving the dose to the baby is more direct, is cheaper (in that it requires analysis of fewer samples), provides additional important information on total body water, and is the only method using deuterium that is suitable for objectively measuring milk intake in formula fed infants. The procedure is non-invasive and requires only a small oral dose of labelled water (which is not radioactive) and daily sampling of saliva or urine; these can often be undertaken by parents without the intrusion of an investigator into the home. Deuterium dilution is the method of choice when the infant breast feeds frequently. ${ }^{6}$ The relatively long study period minimises error due to daily variation in intake. Apart from its research applications, we foresee a role for this technique in clinical practice for outpatient investigation of infants for whom data on milk intake may influence diagnosis or management. Such investigation would also avoid the discouraging effect that test weighing has on some mothers whose milk production is marginal.

We thank Farley Health Products for supplying the formula and for financial help. GE has a grant from Ross Laboratories and SBR holds the Drummond fellowship.

\section{References}

' Coward WA, Whitehead RG, Sawyer MB. Prentice AM, Evans J. New method for measuring milk intakes in breast-fed babies. Lancet 1979;ii:13-4.

2 Orr-Ewing AK, Heywood PF, Coward WA. Longitudinal measurements of breast milk output by ${ }^{2} \mathrm{H}_{2} \mathrm{O}$ tracer technique in rural Papua New Guinean women. Hum Nut Clin Nutr 1986:40C:(in press).

${ }^{3}$ Infante C, Lara W, Vio F. Isotope dilution measurement of breast-milk production in Chilcan urban mothers. Hum Nutr Clin Nutr 1985;39C:379-86.

${ }^{4}$ Butte NF. Garza C. Smith EO, Nichols BL. Evaluation of the deuterium dilution technique against the test weighing procedure for the determination of breast milk intake. Am J Clin Nutr 1983;37:996-10)(3).

5 How TV. Ashmore MP, Rolfe P. Lucas A, Lucas PJ, Baum JD. A Doppler ultrasound technique for measuring human milk flow. J Med Eng Technol 1979:3:66-71.

" Coward WA. Measuring milk intake in breast-fed babies. J Ped Gastroenterol Nutr 1984;3:275-9.

7 Whitehead RG, Paul AA. Human lactation, infant feeding, and growth: secular trends. In: Gracey M, Falkner F, eds. New York: Raven Press, 1985;84-122.

" MacFarlane WV. Howard B. Sieberg BD. Tritiated water in the measurement of milk intake and tissue growth of ruminants in the ficld. Nature 1969:221:578-9.

" Coward WA, Cole TJ, Gerber H, Roberts SB, Fleet I. Water turnover and the measurement of milk intake. Pflugers Arch 1982:383:344-7.

10 Vio FR, Infante CB, Lara WC. Mardones-Sautander F. Rosso PR. Validation of the deuterium dilution technique for the measurement of fluid intake in infants. Hum Nutr Clin Nutr 1986;40C:327-32.

$"$ Roberts SB. Coward WA. Schlingenseipen K-H. Nohria V. Lucas A. Comparison of the doubly labelled water $\left({ }^{2} \mathrm{H}_{2}{ }^{1 x} \mathrm{O}\right)$ method with indirect calorimetry and a nutrient balance study for simultaneous determination of energy expenditure, water intake and metabolisable energy intake in preterm infants. $A m$ $J$ Clin Nutr 1986:(in press).

12 Fomon SJ, Haschke F, Ziegler EE, Nelson SE. Body composition of reference children from birth to age 10 years. Am J Clin Nutr 1982:35:1169-75. 
13 Bland JM, Altman DG. Statistical methods for assessing agreement between two methods of clinical measurement. Lancet 1986;i:307-10.

Correspondence to Dr A Lucas, Medical Research Council Dunn Nutrition Unit, Downhams Lane, Milton Road, Cambridge.

Received 10 February 1987

\section{Commentary}

\section{N F BUTTE AND C GARZA}

Baylor College of Medicine, Houston, Texas, USA

Lucas et al have compared the measurement of formula intake by the deuterium dilution technique and by weighing formula bottles over a seven day period and have shown close agreement between the two methods. ${ }^{1}$ They refer to our paper in which we concluded that the deuterium dilution technique overestimates milk intake, ${ }^{2}$ and this requires some elaboration.

Our trial attempting to validate the method was designed according to the original protocol reported by Coward et al. ${ }^{3}$ Differences in the way in which we used the method compared with that of Lucas et al require critical evaluation. The equilibration period of two hours that we used to calculate total body water was insufficient; in experiment 2 , however, values of total body water predicted from samples taken two hours after the dose of isotope had been given were only $2 \cdot 7 \%$ higher than those obtained by extrapolation from the exponential curve of decay of the isotope to the time of the start of the experiment. Because the half life of water in infants is about three days, assessment of milk intake by the deuterium dilution technique over 48 hours is probably too short, although agreement between methods was not improved when we extended the experiment to 120 hours. Deuterium enrichment analysis was performed at the Dunn Laboratory in both our study and theirs. In our study it was done on a Micromass $602 \mathrm{D}$ spectrometer and an Aqua-sira mass spectrometer; possibly better precision and accuracy were achieved by Lucas $e t$ al in their study.

The short duration ( 48 hours) of the test weighing session was an important limitation of our study. We now know that the estimate resulting from a 48 hour test weighing session should be within about $28 \%$ ( $95 \%$ confidence interval) of an individual infant's intake. ${ }^{4}$ Although this shortcoming led to a less precise estimate, it would not result in a systematic overestimation.

The way in which we calculated milk intake from the results obtained with the deuterium dilution technique was different from that used by Lucas et al; we made no adjustments for the fractionation of deuterium in water vapour. Lucas $e t$ al assumed that an equivalent of $13 \%$ of water intake was subject to fractionation. Although this proportion seems low, they are correct in stating that a $100 \%$ error in this figure would result in about a $1 \%$ error in water output. More importantly, they incorportated a correction factor of $5.7 \%$ and assumed this to be insensible water intake. This value was derived from a previous experiment with preterm infants and was the difference in intake observed between weighed records and results obtained by deuterium dilution. Although it may encompass insensible water influx, it also includes other possible sources of error.

Water influx through the skin and respiratory passages may be a potential, uncontrollable source of error in the 'dose to the infant' version of the deuterium dilution technique. The input of water vapour through the skin should be proportional to ambient humidity and the permeability of the skin to water. ${ }^{5}$ Influx through the lungs should be related to respiratory minute volume and ambient humidity. If ambient water is depleted compared with the body's enrichment, water flux will be overestimated. The effects of unlabelled ambient water vapour at various relative humidities on water influxes measured using tritium were shown in kangaroo rats. ${ }^{5}$ With absolute humidities ranging from 3.8 to $19.8 \mathrm{mg} \mathrm{H}_{2} \mathrm{O} / 1$ air water fluxes were overestimated by 7.7 to $44.2 \%$, respectively. To account for this source of error variations in ambient humidity, skin permeability, surface:volume ratio, and minute volume would have to be considered in the calculation of water flux. Application of a constant correction factor may not be appropriate in environments where humidity varies daily, and the differences between indoor air conditioned and outdoor settings must be taken into account, as would be the case in Houston, Texas, where our own studies were conducted.

Recent preliminary findings from our laboratory, however, suggest that water influx may present only a minor source of error in the 'dose to the infant' deuterium dilution method. We have found that formula intakes predicted from deuterium dilution were only slightly higher than values obtained from direct weighing of formula bottles. Milk intakes of breast fed infants were consistently overestimated by the deuterium dilution technique when compared with values obtained by five day test weighings to the order of $10 \%$ more than were formula intakes. Because there is no obvious reason for the difference in water flux dynamics of breast fed and formula fed infants we must evaluate the test weighing procedure critically. Our measurements of 